\title{
N Design - Um panorama sobre a história do Encontro Nacional dos Estudantes de Design
}

\author{
N Design - An overview of the history of the National Design Students' Meeting
}

DIOGO, Gabriel; Istituto Europeo di Design - SP

gabrieldiogof@gmail.com

\begin{abstract}
Resumo
Este artigo é o resultado da pesquisa sobre o N Design - Encontro Nacional dos Estudantes de Design -, refletindo sobre a deficiência na organização, documentação de suas memórias e registro existente durante seus quase 30 anos de existência. Apresenta um breve histórico do encontro, desde sua idealização até a realização da primeira edição, em 1991, na cidade de Curitiba, e outras reflexões obtidas durante o processo de desenvolvimento deste trabalho. A pesquisa se deu através de entrevistas, relatos e análise materiais existentes relacionados ao encontro, conteúdos esses que são explanados no presente artigo.
\end{abstract}

Palavras Chave: N Design; movimento estudantil; encontros estudantis.

\begin{abstract}
This article is the result of a research on the N Design - Reflecting on the deficiency in organization, documentation of its memories and existing record during its almost 30 years of existence. It presents a brief history of the meeting, from its idealization to the first edition, in 1991, in the city of Curitiba, and other reflections obtained during the development process of this work. The research was conducted through interviews, reports and analysis of existing material related to the meeting, which are further explained along the article.
\end{abstract}

Keywords: N Design; student movement; scholar encounters. 


\section{Introdução}

Este projeto surge através da compreensão da importância que os encontros estudantis desempenham na vida acadêmica e pessoal de quem deles participa. O movimento estudantil representa um grande valor para seus participantes e, de fato, tem um notável poder de transformação, seja na esfera acadêmica, ou até mesmo social. Ao participar desse tipo de movimento, os jovens estudantes de Design passam a se sentir empoderados e tendem a se tornar mais ativos política e academicamente, dentro ou fora das suas instituições de ensino.

Mais especificamente, o que esta pesquisa explora é o $\mathrm{N}$ Design, o Encontro Nacional dos Estudantes de Design, um evento itinerante, sem fins lucrativos, feito por e para estudantes, que acontece todos os anos desde 1991. Atualmente é o grande responsável pelo fomento do movimento estudantil de Design no Brasil. Em sua 27ạ edição, o encontro já passou por 15 cidades do país durante 27 anos de história, promovendo, assim, uma integração entre pessoas de todas as regiões, por isso sua regra de itinerância.

Seu objetivo principal é a união e a integração de estudantes de Design de todo país, a fim de gerar discussões relevantes acerca do ensino e da prática profissional, imergindo o participante durante uma semana em conteúdos como palestras, mesas-redondas, rodas de conversas, festas e apresentações de trabalhos.

Apesar de todo a importância histórica atrelada ao encontro, nota-se uma grande deficiência na documentação dos registros e das memórias relacionadas ao evento. Existem inúmeros registros espalhados por todos os cantos do país - quase sempre nas instituições de ensino que serviram de sede - e muitas histórias desconhecidas podem e precisam ser resgatadas. Histórias que podem contribuir para que a essência do N Design mantenha-se viva pelas próximas gerações de estudantes de Design.

No processo de desenvolvimento deste trabalho, diante da dificuldade de entrar em contato com materiais, atrelada a escassez de artigos e outros textos referenciais relacionados ao $\mathrm{N}$ Design, foram realizadas 18 entrevistas com pessoas que, em algum momento durante seu período universitário, fizeram parte da comissão organizadora de alguma edição, bem como figuras importantes da história do encontro. Dessas entrevistas, juntamente com a análise de outros materiais encontrados durante a pesquisa, foram retirados os dados e informações que compõem este breve histórico do N Design.

\section{Histórico do Encontro Nacional dos Estudantes de Design}

O N Design (Encontro Nacional dos Estudantes de Design) é um evento de cunho acadêmico, político, social, científico e cultural, sem fins lucrativos e é realizado por uma comissão organizadora (CONDe - Comissão Organizadora do N Design), composta majoritariamente por estudantes de diferentes instituições da cidade sede da edição atual, podendo ou não, conter estudantes de outras cidades ou estados. Seu principal objetivo é promover a interação entre os estudantes de Design de todo o Brasil, a fim de gerar discussões relevantes sobre produção acadêmica, campo profissional, ensino, além de questões que, não necessariamente, estão relacionadas ao universo do Design por inteiro, mas que orbitam em volta do campo de atuação, colocando o estudante num ambiente imersivo de difusão de conhecimento e discussões acerca da sociedade. É o grande responsável pelo fomento do movimento estudantil de Design no país atualmente. Apesar da sua primeira edição datar de 1991, sua história começa anos antes durante 
outro Encontro da área.

Desde 1979, quando acontece a primeira edição do ENDI (Encontro Nacional de Desenhistas Industriais, que reuniu diversos profissionais e acadêmicos da área do Desenho Industrial para discutir questões relevantes ao campo de atuação, tais como Regulamentação da profissão, Ensino de Desenho Industrial, Desenho Industrial e Subdesenvolvimento, Desenho Industrial e Indústria) (BRAGA, 2016), na UERJ, os estudantes, assim como os profissionais, passam a ter um espaço mais aberto para discussão de assuntos relacionados ao Design e ao ensino, algo de extrema importância para a profissão (Revista NDesign, 1991). Ainda segundo a Revista NDesign (1991) o encontro ganhou grande visibilidade no corpo estudantil, e a cada edição aumenta o número de alunos participantes, chegando ao ponto em que durante a 4a edição, em Belo Horizonte, uma comissão foi formada para discutir a viabilidade e necessidade da criação de encontro próprio para a discussão estudantil, com questões diretamente relacionadas ao ensino e práticas acadêmicas. Toda a discussão se perdeu nos anos seguintes, o que culminou na não participação da comissão durante o 5ㅇ ENDI em 1988 (que coincidentemente ou não, aconteceu em Curitiba), o que pode ser justificado graças a efemeridade da vida acadêmica, tendo em vista que, em geral, as gerações de estudantes nas universidades duram de quatro a cinco anos (Revista NDesign, 1991).

Nas duas últimas edições supracitadas, a participação dos estudantes representava mais de $70 \%$ do número total de inscritos, o que segundo a Revista NDesign (1991) reforçava ainda mais a necessidade de um espaço próprio para o corpo estudantil de Design, que muitas vezes não tinha abertura para participar dos grupos de trabalho e rodas de discussão dentro dos encontros profissionais.

As discussões sobre esse novo encontro que se anunciava, amadurecem nos anos seguintes e em 1989 acontece um workshop realizado pelo LBDI (Laboratório Brasileiro de Desenho Industrial), que reuniu diversos coordenadores e professores para discutir os rumos do ensino de Design ao redor do Brasil, que posteriormente gerou uma lista de contato com as instituições de desenho industrial da época, facilitando o contato dos estudantes que almejavam um encontro cada vez mais plural (Revista NDesign, 1991).

Conforme descrito na Revista NDesign (1991), aproveitando este mailing produzido, juntamente com a infraestrutura da 1a Bienal Brasileira de Design, que também aconteceu em Curitiba e contava com alguns alunos do CADI - UFPR acompanhando de perto toda a articulação da organização, foi feito contato com todas as 26 instituições do Brasil listadas, com a finalidade de reunir representantes estudantis para uma discussão sobre o encontro de estudantes, já numa esfera maior de participação. Desse contato surgiu o 10 Pró-ENED (Pró Encontro Nacional de Estudantes de Design), que acontece em outubro de 1990, paralelamente à 1a Bienal Brasileira de Design, tendo como participação as instituições que foram até Curitiba para a visita da exposição. Estavam presentes apenas representantes da UFPR (Universidade Federal do Paraná), PUC-PR (Pontifícia Universidade Católica do Paraná), CEFET-PR, ESDI (Escola de Desenho Industrial), UFRJ (Universidade Federal do Rio de Janeiro) e a Faculdade de Belas Artes de São Paulo. A falta de centros acadêmicos estruturados ou pela brevidade de sua história, poucas instituições tiveram contato com os estudantes (Revista NDesign, 1991).

Nesse primeiro momento foi aprovada a ideia de realizar o encontro de estudantes em âmbito nacional, mas por falta de quórum não foi decidida sua sede, cabendo à UFRJ a 
organização de um 2o Pró-ENED (Revista NDesign, 1991).

A segunda edição, que aconteceu em dezembro do mesmo ano, foi realizada a fim de definir a sede do 10 encontro de estudantes de Design e seu nome. Como só houve a candidatura do CADI-UFPR, Curitiba foi aprovada como cidade sede por unanimidade, em uma reunião que contou com representantes de dez universidades: UFSM (Universidade Federal de Santa Maria), Mackenzie, Mauá, PUC-Rio (Pontifícia Universidade Católica do Rio de Janeiro), ESDI, UFRJ, UFMA (Universidade Federal do Maranhão), Faculdade da Cidade, FUMA (Fundação Mineira de Artes Aleijadinho) e UFPR. O nome escolhido para o encontro foi "N Design" (Revista NDesign, 1991).

Como uma maneira de fortalecer o movimento estudantil na instituição, segundo a Revista NDesign (1991), durante o período entre os dois Pró-ENEDs, o centro acadêmico da UFPR começa a produzir o "Ovo de Colombo", um fanzine que teve como intenção unir os estudantes da universidade com a organização do encontro, além de servir como divulgação do próprio evento, gerando um estímulo para a reestruturação do centro acadêmico.

Em 1991, enfim, é realizado o primeiro N Design, na cidade de Curitiba, como havia sido decidido anteriormente. O evento aconteceu no Centro de Criatividade de Curitiba, realizado pelos estudantes da UFPR e compareceram aproximadamente 700 estudantes, dando início a história de um dos principais eventos de Design do Brasil.

Figura 1 - Fotografia do 1 ㅇN N Design

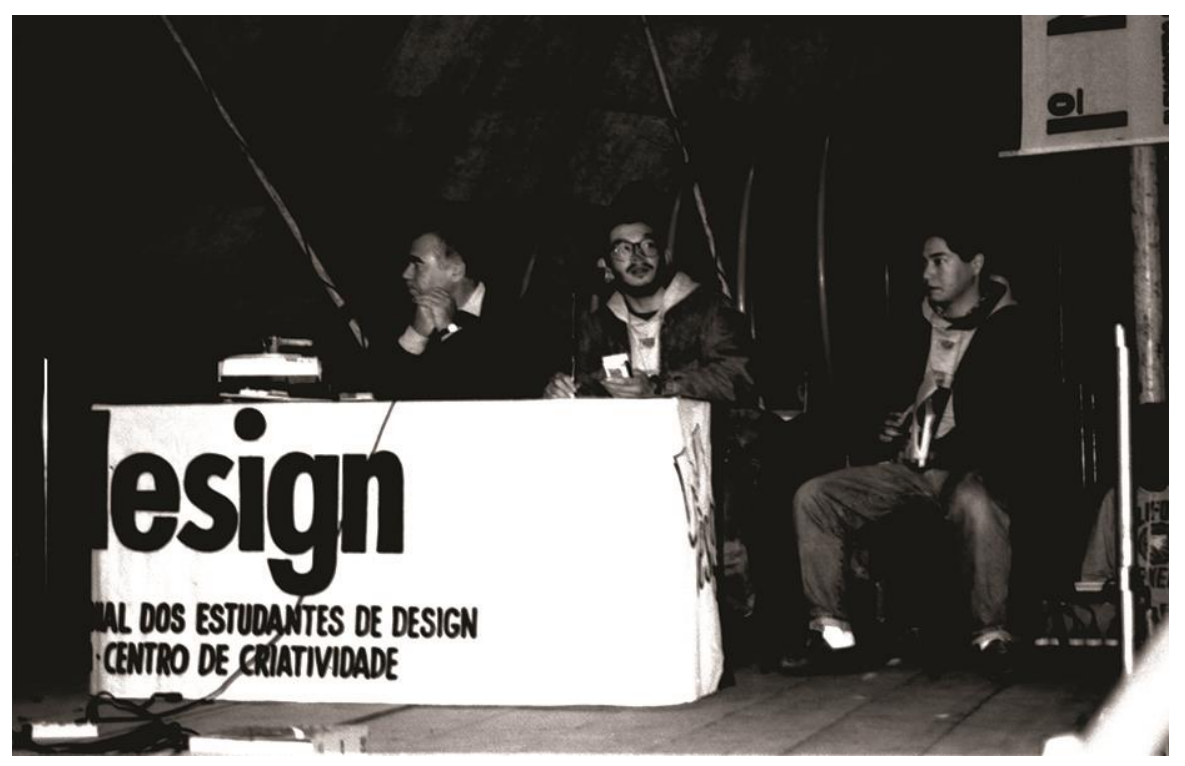

Disponível em: https://www.flickr.com/photos/92226278@N06/10651444535/in/album-72157637237898195/

Acesso em: 10 mar. 2018

\subsection{Edições do N Design}

Tabela 1 - Edições do N Design, cidade-sede e no de encontristas*

Ano Cidade № de encontristas




\begin{tabular}{|c|c|c|}
\hline 1991 & Curitiba-PR & Aprox. 700 \\
\hline 1992 & Santa Maria-RS & Aprox. 900 \\
\hline 1993 & Belo Horizonte-MG & Aprox. 1200 \\
\hline 1994 & Rio de Janeiro-RJ & - \\
\hline 1995 & Recife-PE & - \\
\hline 1996 & São Luís-MA & - \\
\hline 1997 & São Paulo-SP & 882 \\
\hline 1998 & Curitiba-PR & Aprox. 1300 \\
\hline 1999 & Brasília-DF & - \\
\hline 2000 & Salvador-BA & Aprox. 1500 \\
\hline 2001 & Recife-PE & - \\
\hline 2002 & Bauru-SP & Aprox. 1300 \\
\hline 2003 & Belo Horizonte-MG & Aprox. 1400 \\
\hline 2004 & Santa Maria-RS & Aprox. 1900 \\
\hline 2005 & São Luís-MA & Aprox. 800 \\
\hline 2006 & Brasília-DF & Aprox. 2200 \\
\hline 2007 & Florianópolis-SC & 4532 \\
\hline 2008 & Manaus-AM & 1361 \\
\hline 2009 & Olinda-PE & 1715 \\
\hline 2010 & Curitiba-PR & 4575 \\
\hline 2011 & Rio de Janeiro-RJ & 2616 \\
\hline 2012 & Belo Horizonte-MG & 1814 \\
\hline 2013 & Salvador-BA & 1134 \\
\hline 2014 & Goiânia-GO & 1304 \\
\hline 2015 & São Paulo-SP & 1288 \\
\hline 2016 & João Pessoa-PB & - \\
\hline 2017 & Curitiba-PR & 1305 \\
\hline
\end{tabular}

* Nome dado aos participantes do encontro.

Fonte: Autor (2017) 


\section{Análise dos principais materiais produzidos pelas comissões}

Como citado no capítulo anterior, existem muitos registros relacionados ao $\mathrm{N}$ Design, em diversos formatos, mas não há um agrupamento desses conteúdos. No entanto durante o período em que organizaram o $\mathrm{N}$ Design, algumas comissões comprometeram-se a produzir materiais com o intuito de compilar informações sobre o encontro. Encontram-se dois tipos de formatos utilizados pelas comissões: vídeo, como documentário e revista.

Estes registros são essenciais para esta pesquisa e exercem papel importante na história e memória do N Design.

\subsection{Revista NDesign}

Figura 2 - Capa e quarta-capa da Revista NDesign

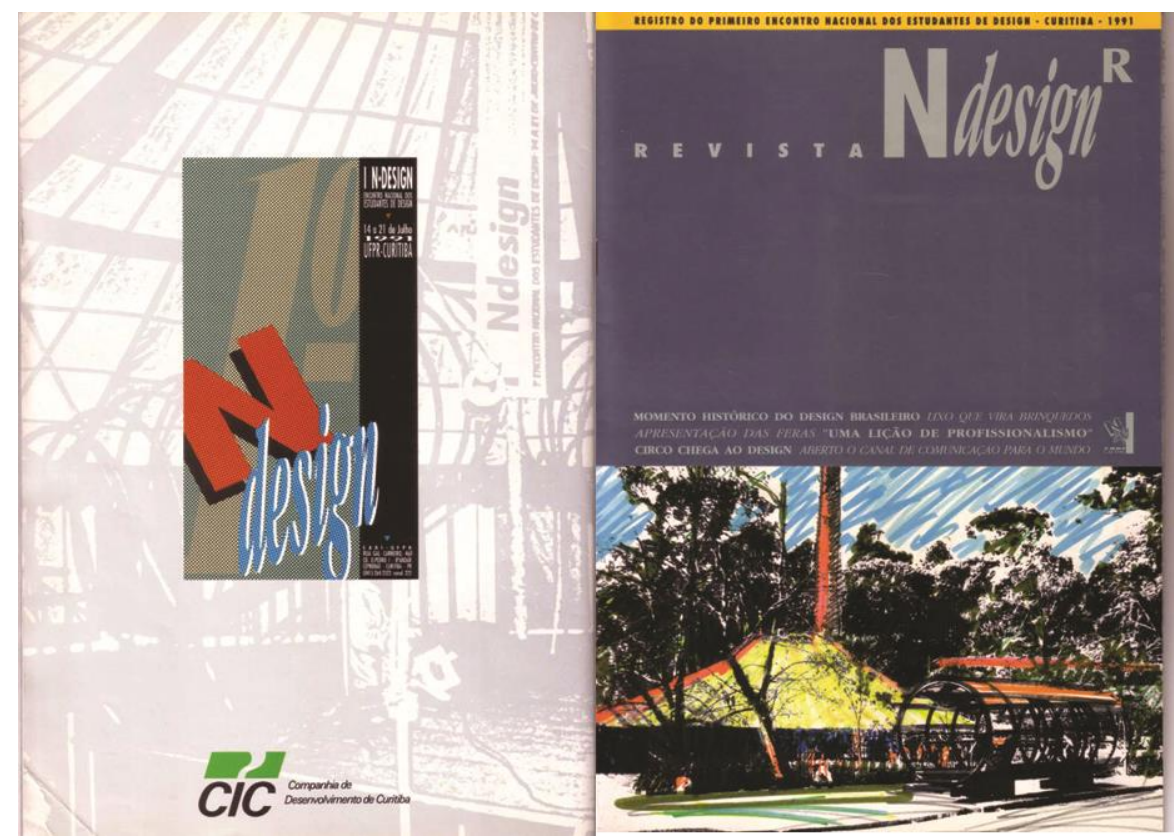

Fonte: Acervo pessoal (2017)

Após o acontecimento da 1 a edição do N Design, foi produzida uma revista que documenta parte do processo de desenvolvimento do encontro por parte da comissão, seus anseios e objetivo. Além disso, é de grande importância por relatar as articulações estudantis durante os ENDIs (Encontro Nacional de Desenhistas Industriais) na década de 1980, um evento direcionado a professores, pesquisadores e profissionais do mercado, que em determinado momento passou a receber um número alto de estudantes que sentiam necessidade de um espaço próprio, com discussões de interesse do corpo estudantil. Entre os resultados obtidos a partir dessas articulações, estão os Pró-ENEDs, eventos realizados por esses estudantes, além do próprio $\mathrm{N}$ Design. 


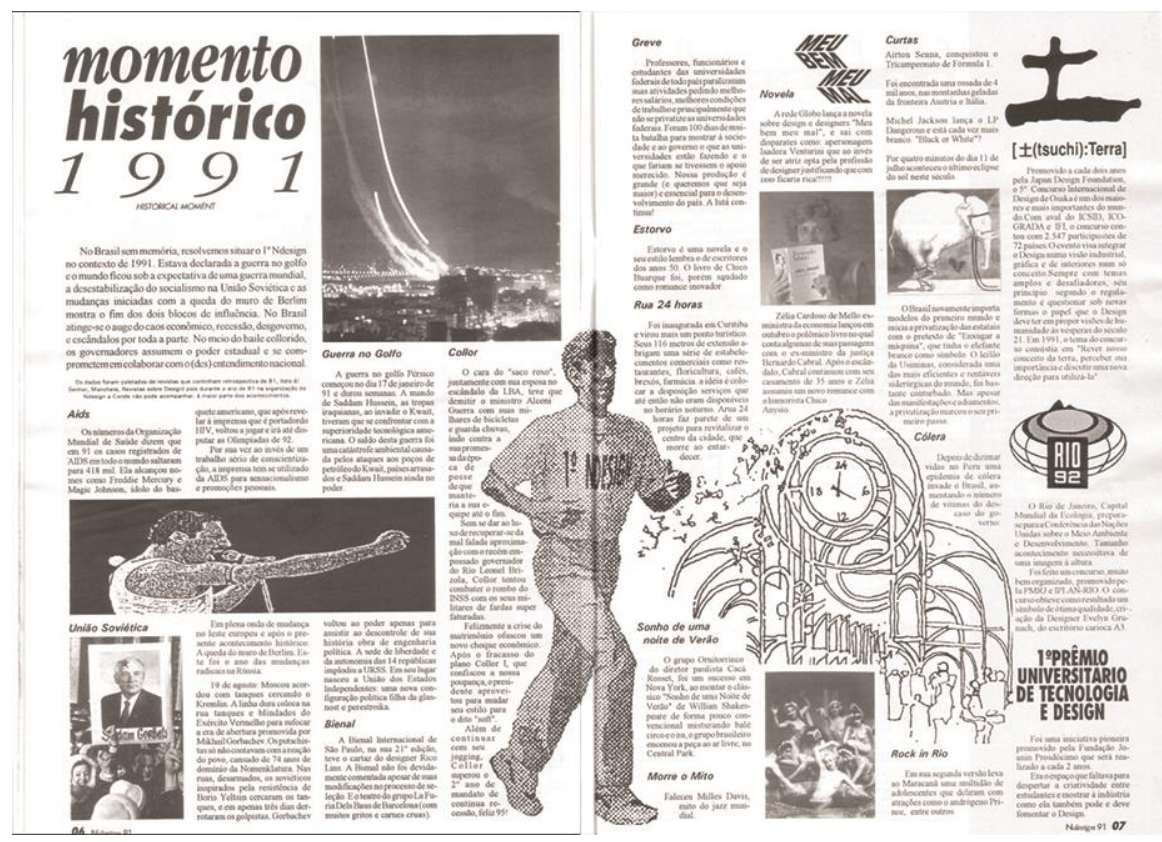

Fonte: Acervo pessoal (2017)

A publicação relata diversas atividades durante o encontro, como por exemplo a Repentina, que consistiu numa oficina de produção de brinquedos com materiais reciclados, a atividade externa realizada no centro da cidade, a lista de trabalhos participantes da exposição presente no local do encontro, a programação diária de atividades e apresenta um panorama geral sobre as plenárias e reuniões. Além disso reuniu o contato de todos os cursos de Design existentes até então, dessa forma facilitou a interação entre os estudantes de todo o país.

Esta publicação é resultado do projeto de graduação de Naotake Fukushima, hoje professor e um dos responsáveis pela criação do N Design (Revista NDesign, 1991).

Esta revista possui um material muito rico sobre o início da história do N Design e exerceu papel fundamental na presente pesquisa.

\subsection{Revista Design - N Design 1997}

Figura 4 - Capa e quarta-capa da Revista Design - N Design 1997

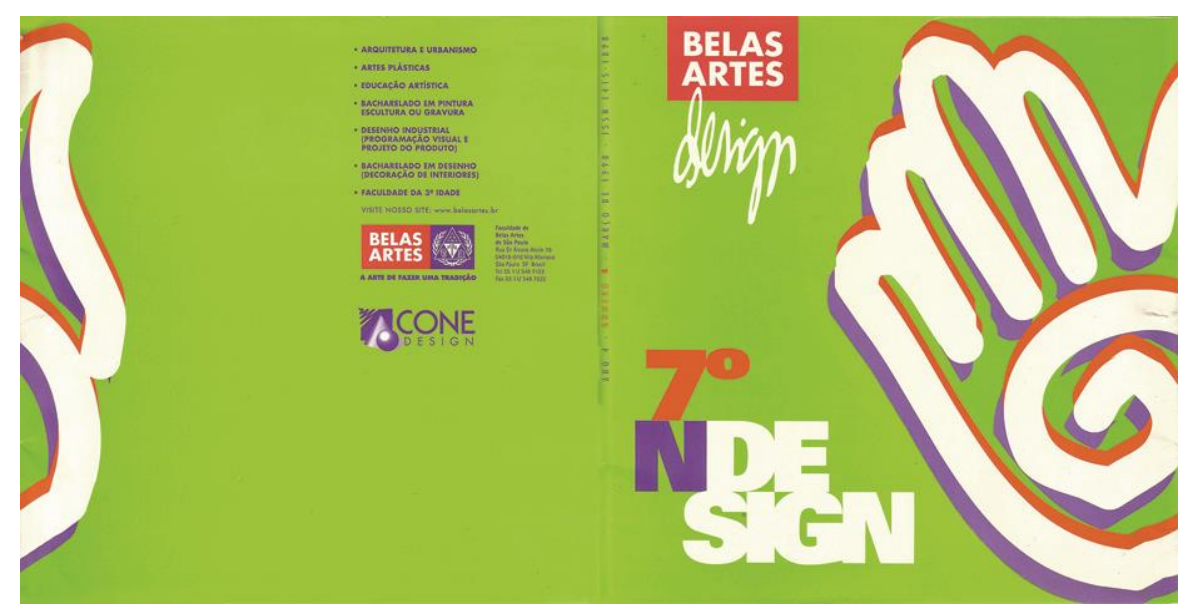


Fonte: Acervo pessoal (2017)

A publicação produzida para a 7ạ edição do N Design, da mesma forma que a produzida para a 1a edição, relata os acontecimentos da semana do encontro.

A revista é, na verdade, uma publicação periódica do Centro Universitário Belas Artes, onde ocorreram as atividades do encontro, que, em sua edição seguinte do acontecimento do encontro, produz um especial sobre a $7 \underline{a}$ edição do $N$ Design.

Figura 5 - Página dupla da Revista Design - N Design 1997
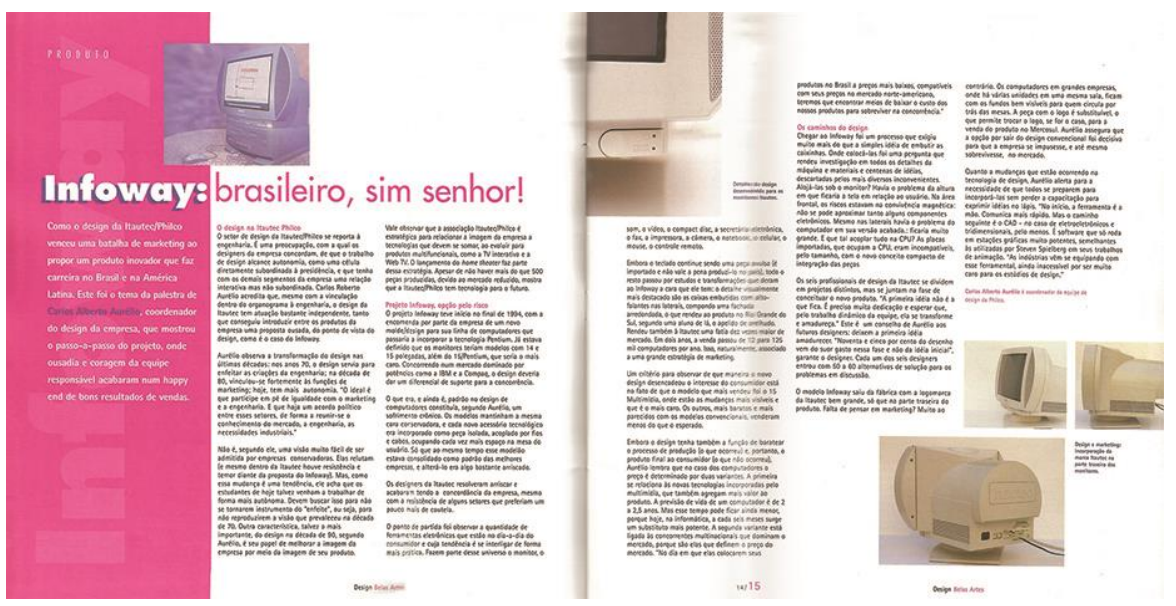

Fonte: Acervo pessoal (2017)

No decorrer da publicação, discorre-se sobre as atividades realizadas no local do encontro, com destaque para uma palestra do designer Hans Donner, além de relatar sobre as mesasredondas e seus temas com certo detalhamento, o que facilita o entendimento e possível conclusão de cada discussão. Este registro apresenta também a programação completa do encontro e teve grande importância para o maior aprofundamento nas questões relacionadas a esta edição.

\subsection{Revista 14ㅇ№sign}

A comissão organizadora do 14 N Design gerou materiais muito interessantes de registros sobre a edição do encontro. Um dos resultados foi a revista que, assim como as outras produzidas pelas comissões citadas anteriormente, apresenta um panorama geral sobre os acontecimentos durante toda a semana do encontro assim como todo o pensamento conceitual por trás do evento.

Figura 6 - Capa e quarta-capa da Revista 14ㅇNDesign 


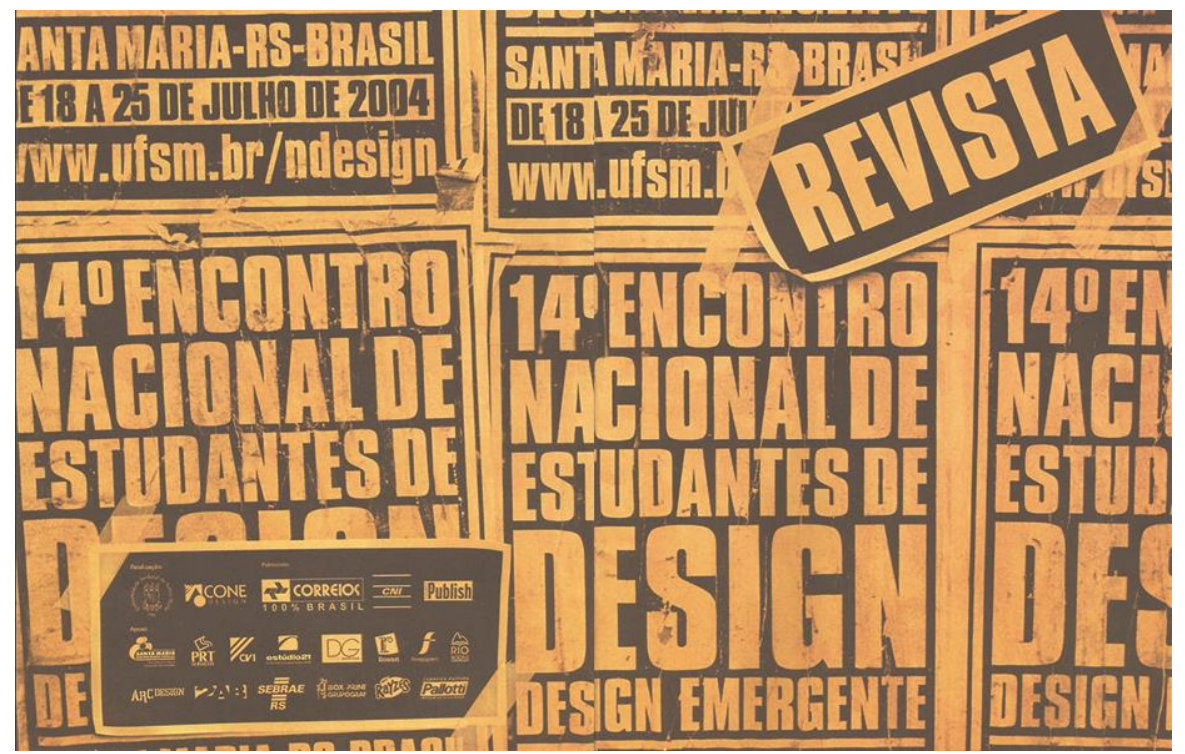

Fonte: Acervo pessoal (2017)

O conteúdo da revista é dividido de acordo com os dias da semana e, dessa forma, é apresentada de forma linear para que o leitor pudesse acompanhar as atividades de forma cronológica. Os conteúdos das atividades são apresentados de forma muito detalhada, assim como nas outras edições, é possível ter um bom entendimento da discussão e quais seus resultados.

Figura 7 - Dupla da Revista 14 NDesign

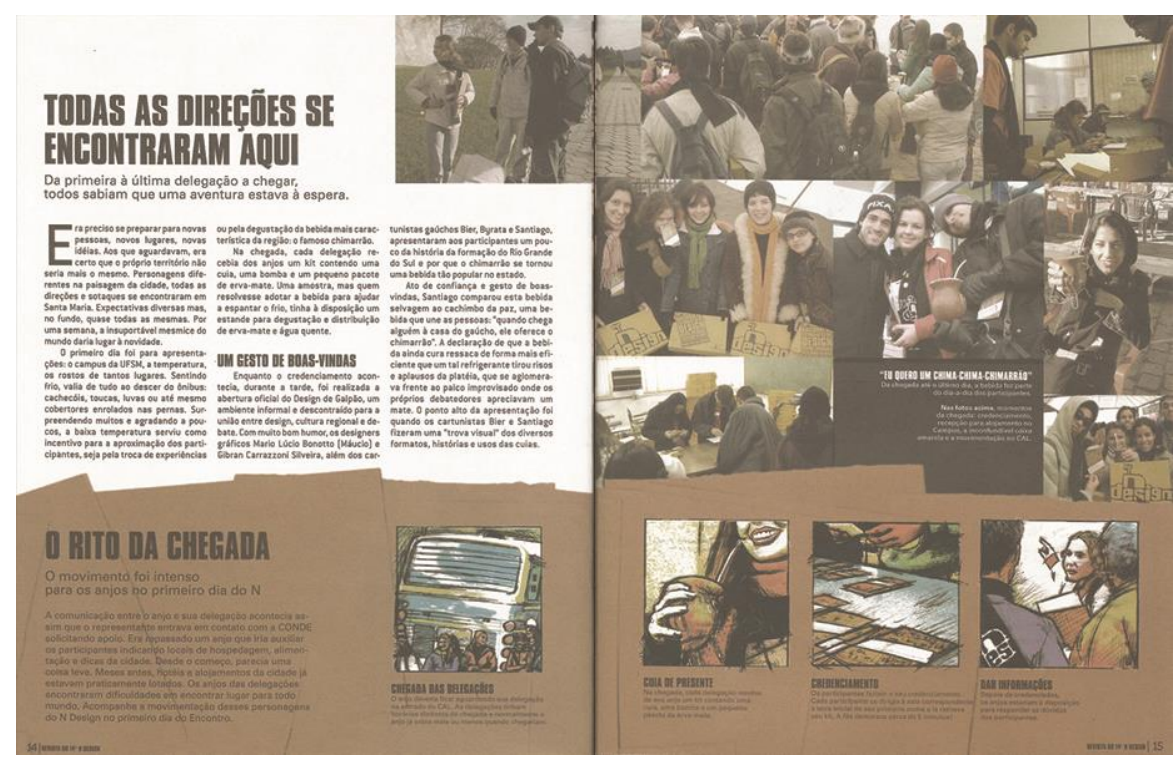

Fonte: Acervo pessoal (2017)

Este trabalho, assim como as outras publicações aqui citadas, é muito competente e cumpre bem o seu papel. É completo e um ótimo exemplo de como tornar real e manter viva a memória e o registro do $\mathrm{N}$ Design. 


\subsection{Documentário 14 N Design}

Além da revista produzida pela comissão organizadora através dos materiais captados durante a semana do encontro, foi produzido também um DVD contendo um documentário, com o mesmo intuito de apresentar a concepção do encontro, até os acontecimentos da semana.

O documentário contém entrevistas com os organizadores, contando suas experiências no encontro, imagens captadas antes do início e trechos de atividades realizadas. Seu conteúdo é dividido pelos dias da semana, podendo ser assistido na íntegra ou especificamente um recorte. Além disso, pelo DVD é possível acessar um álbum de fotos tiradas durante encontro.

\subsection{Um balaio de encontros}

O documentário foi dirigido e produzido no ano de 2008, pelo Estúdio Boana, um coletivo de estudantes que tinha como objetivo promover o movimento estudantil em seus trabalhos. Diante disso, foi realizado um documentário sobre a 17ạ edição do N Design, que aconteceu em Florianópolis. O documentário conta com depoimentos de diversos membros da comissão organizadora, relatando a experiência de participar da organização de um evento desse porte, antes e durante o encontro, apresentando imagens de diversas atividades que aconteceram durante a semana. Além disso, conta com outros depoimentos de pessoas que participaram do encontro, também relatando sua experiência como encontrista.

O documentário é muito completo e tem grande relevância para a presente pesquisa, uma vez que serviu como base para o entendimento e compreensão dos objetivos da comissão na realização do encontro e como foi sua dinâmica durante os 7 dias de evento.

\subsection{MAKING OF N Manaus 2008}

O documentário apresenta com certo detalhamento o processo de desenvolvimento da 18a edição do N Design, realizada em Manaus durante o ano de 2008. Os membros da comissão organizadora relatam suas experiências durante os anos anteriores, desde quando conheceram o $\mathrm{N}$ Design até a possível candidatura como cidade-sede e, posteriormente, a execução do evento em si.

São mostradas diversas iniciativas realizadas pela comissão a fim de arrecadar recursos e apoiadores para a realização do encontro, de forma que se torna mais clara as dificuldades e caminhos a serem percorridos pelas comissões a partir do momento em que são eleitas como sede do $\mathrm{N}$ Design. Além disso, o documentário também apresenta relatos de pessoas que participaram do encontro, contando algumas experiências antes e durante o evento.

Mais uma vez, este documentário traz muitas informações interessantes e importantes, não só para esta pesquisa, mas também para todos que se interessam pelos encontros estudantis e sua história.

\subsection{Documentário N Jeitos 2012}

Este documentário, realizado pela própria comissão organizadora, assim como os demais documentários produzidos para outras edições, apresentam de forma detalhada como se deu a construção do encontro. Neste caso, o foco maior é a semana do evento em si, apresentando imagens de diversas atividades, palestras, mesas-redondas e festas.

Um grande diferencial deste documentário é apresentar depoimentos de convidados que 
realizaram algum tipo de atividade no encontro, relatando sua experiência durante aquela semana e como estudante participante do N Design no seu período de graduação.

Os membros da comissão também têm seu espaço, mais uma vez relatando sua experiência e vivência durante a construção e, posteriormente, realização do encontro.

\subsection{Visita ao CADI UFPR}

Em março de 2017, durante o processo de pesquisa do presente projeto, foi realizada uma visita ao CADI UFPR (Centro Acadêmico de Desenho Industrial da Universidade Federal do Paraná), que possui um grande acervo de materiais relacionados ao $\mathrm{N}$ Design, principalmente que dizem respeito às edições realizadas em Curitiba, como por exemplo, a 1aㅡ, que possui um grande número de documentos guardados na sala do CADI.

Figura 8 - Parede da sala do CADI-UFPR

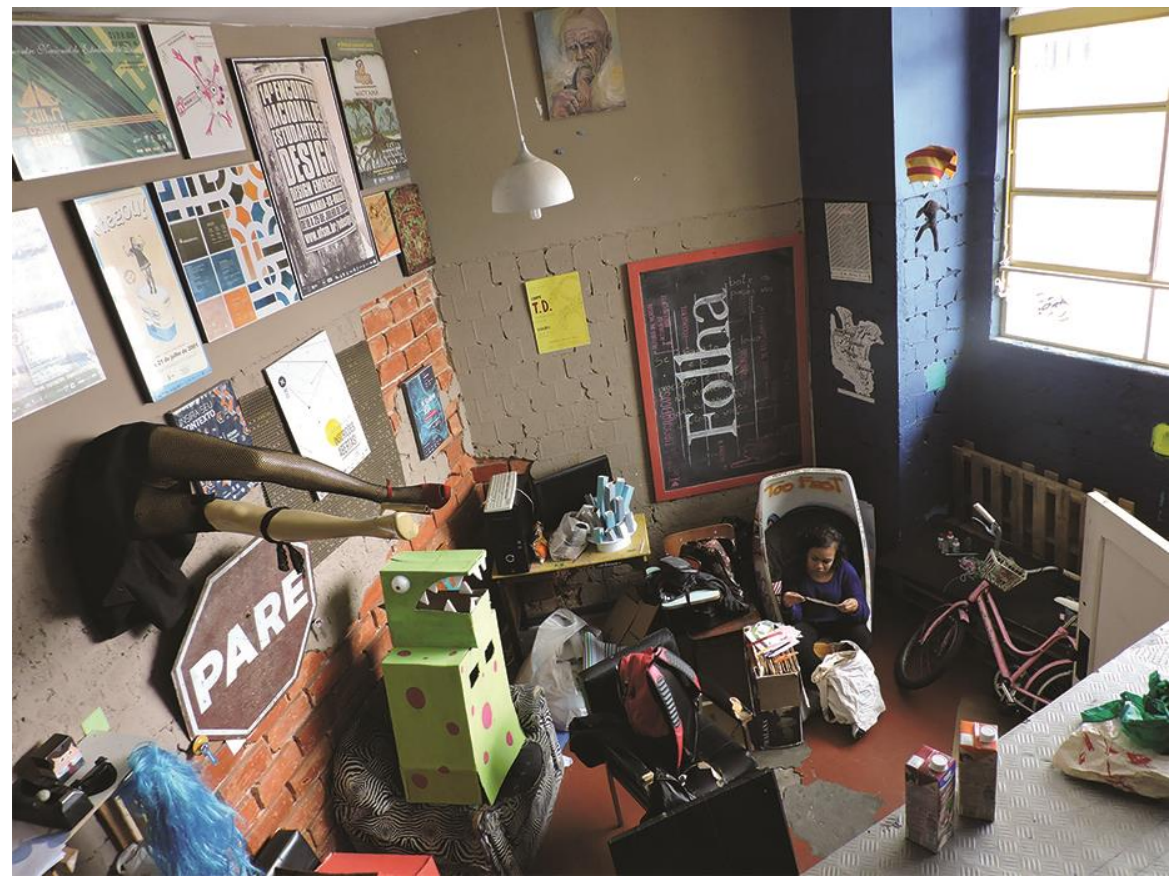

Fonte: Acervo pessoal (2017)

Muitos materiais relacionados a 8a e 20ạ edição também compõem o acervo do centro acadêmico, este segundo, por ser mais próximo aos dias atuais, conta com um número mais completo de materiais.

Além disso, estão armazenados materiais relacionados a outras edições, como por exemplo, guias de programação, bolsas, camisetas e outros materiais distribuídos pelas comissões aos participantes.

A atitude dos membros do CADI UFPR durante os anos, de manter o acervo sempre atualizado é louvável, afinal, estes materiais são de extrema importância para que a memória do $\mathrm{N}$ Design não seja apagada pelo tempo, no entanto, até a presente pesquisa, nota-se uma falta de cuidado com o acervo, uma vez que todos os materiais ficam armazenados em um armário claramente desorganizado, junto de muitos outros materiais relevantes ao CADI. Muitos dos 
materiais relacionados ao $\mathrm{N}$ Design não são colocados em pastas ou alguma outra forma organizacional, o que torna seu acesso dificultado e desorganizado.

Em conversas com membros do CADI, entende-se o desejo de organizar e catalogar todos esses materiais, de forma que possa servir como material de pesquisa mais acessível, no entanto, ainda pouco foi feito para este fim.

Os materiais apresentados nesse capítulo são muito importantes para a manutenção das memórias do N Design através dos anos. O desejo das comissões de documentar, seja em formato de revista ou em formato de vídeo, as edições do encontro colaboram para que uma nova camada de estudantes conheça o histórico e os diferentes modelos que se desenvolveram no decorrer da história. Não à toa, as edições do encontro que possuem algum tipo de registro, são facilmente estudadas e conhecidas pelas pessoas que frequentam o evento. Assim como, são as que possuem dados mais ricos e um número maior materiais e documentos disponíveis, tanto impressos quanto digitais.

É mais que necessária a preocupação das próximas comissões em documentar os registros, produzir materiais de divulgação e de apresentação das edições do N Design, para que dessa forma, torne-se ainda mais ampla e acessível a história do encontro.

\section{Reflexões}

Com 26 anos de história, o N Design, naturalmente, passou por muitas mudanças desde suas primeiras edições até os dias de hoje. Essas mudanças se dão por diversos motivos como, por exemplo, a evolução tecnológica neste período, que influenciou o encontro em vários aspectos. Um dos pontos em que é notória a influência dessa evolução é nas inscrições dos participantes, que por muito tempo foram realizadas através de fichas de inscrição, que eram enviadas para as universidades, preenchidas e reenviadas às comissões, junto do valor total da inscrição. Depois da popularização do uso de computadores pessoais, as inscrições passaram a ser realizadas pela internet, aumentando a agilidade e a facilidade, tanto para a comissão quanto para o participante.

É possível notar essa influência também na relação dos conteúdos propostos pelas comissões. Nas primeiras edições a grande maioria dos conteúdos era direcionada ao Design de Produto ou ao Design Gráfico, que pode ser compreendido graças ao número reduzido de cursos de Design espalhados pelo país naquela altura, quando eram oferecidos apenas cursos direcionados ao desenho industrial e à comunicação visual.

No fim da década de 1990, com a popularização de novas tecnologias e o surgimento de novos segmentos na área do Design como, por exemplo, o webdesign, os conteúdos propostos passaram a abordar esses assuntos dada sua grande relevância, uma vez que os estudantes muitas vezes não tinham acesso facilitado a esses assuntos em suas regiões. Dessa maneira, as edições do $\mathrm{N}$ Design mantiveram-se sempre atualizadas, com discussões pertinentes dentro do seu contexto social e histórico.

Atualmente percebe-se uma grande preocupação das comissões e dos participantes em discutir questões relacionadas ao Design Social, Design de Serviços, Design Estratégico, áreas crescentes nos dias de hoje e, além disso, outras que não necessariamente estão ligadas diretamente ao Design, mas que relacionam-se à sociedade e ao contexto atual. Fazendo essa breve avaliação dos conteúdos, nota-se também que os conteúdos levados e propostos nos encontros, em geral, são reflexos do mercado profissional do Design. 
Através da breve análise do histórico do $\mathrm{N}$ Design nesses últimos 27 anos também é possível notar que em quase todos os anos, o $\mathrm{N}$ Design aconteceu nas capitais dos estados, excetuando-se poucos casos, como por exemplo, os das edições de 1992 e 2004 (Santa Maria), 2002 (Bauru) e 2009 (Olinda). Isso pode ser compreendido graças ao grande número de cursos de Design centralizados nesses municípios, além de representarem os centros econômicos de seus estados. Em todas as 27 edições, somente em 5 casos o N Design não aconteceu em um dos 30 municípios com maior PIB no Brasil, segundo dados do IBGE ${ }^{1}$, o que pode ser interpretado com um direcionamento do evento para municípios com maior concentração de renda. Diante desses dados, é possível aproximar-se de algumas conclusões, como uma possível elitização do Design no Brasil, visto que não só os encontros estudantis aconteceram, mas também a maioria dos cursos e empresas se concentram nos principais centros econômicos do país. Esse ponto também pode gerar um bom questionamento para quem realiza esse tipo de evento, não só o $\mathrm{N}$ Design, mas também os outros encontros estudantis, uma vez que a própria realização do evento em cidades menores ou que não nas capitais, pode se tornar um ponto de reflexão para quem participa. Este assunto pode ser destrinchado de diversas maneiras e é muito importante que seja. No entanto, não cabe à presente pesquisa aprofundar-se tanto, logo, fica a expectativa de novos trabalhos que surjam sobre os encontros estudantis e abordem essa questão com a profundidade necessária.

Analisando o número de participantes de cada edição do N Design é possível perceber que, na verdade, o grande número de edições consecutivas não representou um crescimento no número de participantes a cada ano, e sim que, durante a sua história, o N Design viveu (e ainda vive) altos e baixos. Nos primeiros cinco anos houve uma crescente no número de participantes a cada ano, sendo que, na 1a edição, compareceram 700 estudantes e, já na 3a edição, o número subiu para mais de 1000 . Isso representa um sucesso imediato na realização do encontro que caminhava para o seu terceiro ano consecutivo.

A partir da sua décima edição e até hoje, o $\mathrm{N}$ Design manteve-se com um número de participantes superior a 1000, exceto em 2005, quando em São Luís, muito possivelmente pela distância dos grandes centros e o custo que esse deslocamento acarreta, o número de participantes não chegou a 900. Em outros casos o encontro atingiu a marca de 2000 e somente em duas ocasiões ultrapassou o número de 4000 participantes. Nos últimos 7 anos é notória uma decrescente no número de participantes (Tabela 2).

Tabela 2 - Número de encontristas por edições desde 2010

\begin{tabular}{lll}
\hline Ano & Cidade & No de encontristas \\
\hline 2010 & Curitiba-PR & 4575 \\
2011 & Rio de Janeiro-RJ & 2616 \\
2012 & Belo Horizonte-MG & 1814 \\
2013 & Salvador-BA & 1134 \\
2014 & Goiânia-GO & 1304
\end{tabular}

1 Disponível em: <https://www.ibge.gov.br/estatisticas-novoportal/economicas/contas-nacionais/9088-produtointerno-bruto-dos-municipios.html?=\&t=destaques>. Acesso em: 10 mar. 2018 


$\begin{array}{llc}2015 & \text { São Paulo-SP } & 1288 \\ 2016 & \text { João Pessoa-PB } & * \\ 2017 & \text { Curitiba-PR } & 1305\end{array}$

*Número oficial inexistente

Fonte: Autor (2017)

Em 2010 foram 4575 inscritos, nos anos seguintes essa quantidade diminuiu gradativamente e, na última edição, compareceram cerca de 1300 participantes. Apesar dos dados apresentarem essas variações em relação ao número de encontristas presentes nos encontros, é necessário levar em conta que, por o $\mathrm{N}$ Design acontecer a cada ano em uma cidade e um contexto diferente, é muito difícil se chegar a uma conclusão final acerca desse assunto. Cada caso deve ser analisado levando em conta vários aspectos, como por exemplo, o contexto socioeconômico do país em determinada edição, a cidade onde aconteceu o encontro, tendo em vista que alguns lugares têm o acesso mais dificultado por pessoas de outras regiões, seja por distância ou na questão econômica, considerando os valores de passagens viárias ou aéreas. Esses dois últimos apontamentos evidenciam ainda mais uma característica marcante do N Design, assim como outros encontros estudantis de nível nacional, que é a sua itinerância, de forma que, pelo menos uma vez durante o período de graduação, o estudante tenha o acesso mais facilitado, por acontecer mais próximo à sua região. É importante salientar que, durante as pesquisas, alguns números não foram encontrados, o que dificulta a análise desses dados, mas ainda assim foi possivel alcançar algumas conclusões.

Nota-se, então, que o N Design acontece como um organismo vivo, que vive em constante mudança, sempre receptivo a um novo contexto e uma nova realidade, mantendo-se atualizado, ora com maior ora com menor adesão. E, talvez, estas sejam as características principais - e o que mantém vivo o espírito - deste encontro que acaba de completar 27 anos de existência.

\section{Considerações finais}

Com o objetivo central de contribuir com o fomento do movimento estudantil de Design no Brasil, bem como a compreensão da importância do N Design para o cenário do Design brasileiro, este artigo explorou a história e a existência do encontro estudantil que, desde 1991, acontece todos os anos de forma ininterrupta, podendo ser considerado o principal espaço de articulação estudantil voltado aos cursos de Design no país.

Como citado na introdução deste trabalho, na fase inicial do desenvolvimento deste trabalho, a fim de se agrupar mais dados de pesquisa relevantes, foram realizadas 18 entrevistas, que totalizam mais de 20 horas de material bruto de áudio. As entrevistas aconteceram com figuras importantes na história dos encontros, bem como com pessoas que participaram da organização de alguma edição do N Design e foram determinantes para as conclusões obtidas neste trabalho.

Durante as pesquisas, não foi encontrado nenhum trabalho que abordasse tão a fundo o histórico do N Design, bem como sua importância na formação estudantil desde sua criação. Sendo assim, este trabalho pode ser considerado um dos primeiros passos para que o $\mathrm{N}$ Design 
receba seu devido valor dentro e fora da academia e sua importância para a formação dos estudantes seja ainda mais reconhecida. Fica explícita aqui, a expectativa que este trabalho seja continuado nos próximos anos por muitos outros estudantes, apresentando novas visões sobre o encontro, abordando questões não mencionadas nesta pesquisa e a tornando cada vez mais forte.

\section{Referências}

BRAGA, Marcos da Costa; "A Associação Profissional dos Desenhistas Industriais do Rio de Janeiro - APDINS-RJ", p. 143-202. In: Braga, Marcos da Costa. ABDI e APDINS-RJ, 2a edição. São Paulo: Blucher, 2016.

DESIGN BRASIL. NDesign - Encontro Nacional de Estudantes de Design. Disponível em: <http://www.designbrasil.org.br/design-em-acao/n-design/>. Acesso em: 24 abr. 2017.

Revista NDesign. 1991.

Documentário 14 N Design. Santa Maria: 2005. Color.

MAKING OF N Manaus 2008. Manaus: 2009. Color.

N Jeitos 2012. Belo Horizonte: 2013. Color.

Um balaio de encontros. Florianópolis: Boana Estúdio, 2009. Color. 